\title{
OS SIGNIFICADOS DOS PROJETOS DE ESPORTE E LAZER PARA ALUNOS DO INSTITUTO FEDERAL DO NORTE DE MINAS GERAIS ${ }^{1}$
}

Recebido em: $12 / 12 / 2016$

Aceito em: 20/10/2017

\author{
Romualdo Ferreira dos Santos ${ }^{2}$ \\ Instituto Federal do Norte de Minas Gerais \\ Arinos - MG - Brasil \\ Cinthia Lopes da Silva ${ }^{3}$
}

Universidade Metodista de Piracicaba (UNIMEP)

Piracicaba - SP - Brasil

RESUMO: Este trabalho tem como objetivo analisar e identificar os significados dos projetos de esporte e de lazer do Instituto Federal do Norte de Minas Gerais - Campus Januária para alunos do Ensino Médio participantes de tais projetos. Como procedimento metodológico foi realizada pesquisa bibliográfica e de campo, fundamentada em autores das Ciências Humanas e da Educação Física, caracterizando este estudo como qualitativo. A pesquisa de campo foi realizada com rapazes dos cursos de Agropecuária e Informática. As técnicas utilizadas na pesquisa foram entrevistas semiestruturadas, questionário e observação participante. A maioria dos alunos afirmou que os projetos de esporte e lazer são importantes em suas vidas pelo fator da oportunidade de socialização, competição, diversão e em sentido compensatório - obter melhorias para a saúde e quebrar a rotina do dia a dia.

PALAVRAS CHAVE: Atividades de Lazer. Educação Física e Treinamento. Cultura.

\section{THE MEANINGS OF THE SPORT AND LEISURE PROJECTS FOR STUDENTS FROM THE FEDERAL INSTITUTION OF THE NORTH OF MINAS GERAIS}

ABSTRACT: This work has the objective of analyzing and identifying the meanings of the sport and leisure projects from the Federal Institution of the North of Minas Gerais Januaria Campus, for senior high school students from such projects. Bibliographical and field researches were carried out as the methodology procedure, and they were based on Human Science and Physical Education, thus characterizing this study as qualitative. The field research was done with students of Farming and Computing courses. The techniques used in this research were semistructured interviews,

\footnotetext{
${ }^{1}$ Pesquisa de mestrado financiada pela CAPES.

${ }^{2}$ Mestre em Ciências do Movimento Humano pela Universidade Metodista de Piracicaba. Professor do Instituto Federal do Norte de Minas Gerais.

${ }^{3}$ Professora dos Cursos de Graduação em Educação Física e Programa de Pós-graduação em Ciências do Movimento Humano da Unimep.
} 
questionnaires and participant observation. The majority of students said that sport and leisure projects are important in their lives for the opportunities the students have of widening their social network, competing, having fun, and for compensation - health improvements and taking a break from day to day activities.

KEYWORDS: Leisure Activities. Physical Education and Training. Culture.

\section{Introdução}

Durante o ano letivo, os estudantes do Instituto Federal do Norte de Minas Gerais (IFNMG) - Campus Januária têm participado de diversas modalidades coletivas e individuais em competições esportivas municipais e estaduais, promovidas pelas Secretarias de Educação, Esporte e Lazer de Minas Gerais e do Programa Minas Olímpica. Esses alunos participam de competições promovidas pelo próprio Instituto Federal, por meio da Secretaria de Educação Profissional Tecnológica do Ministério da Educação. Nas competições esportivas, os estudantes têm sido incentivados a participar pelos departamentos de ensino e de extensão do campus, principalmente pelo setor de Educação Física, por meio de seus professores, uma vez que a eles ficam destinados o desenvolvimento dos projetos de esporte e lazer. Diretores e professores consideram, ainda, esses projetos como mais uma opção de atividades do contexto do lazer para os alunos no âmbito escolar (sempre que nos referirmos ao esporte ou a outros conteúdos vivenciados no tempo disponível iremos considerar a denominação "atividade do contexto do lazer" e não meramente "atividade de lazer". Isso porque entendemos que o lazer é um fenômeno social). Os projetos esportivos e de lazer acontecem no contraturno das aulas, ou seja, após as obrigações escolares. Tais projetos envolvem diversas modalidades esportivas, tais como: atletismo, futsal, handebol, voleibol, basquete, natação e musculação. 
O esporte pode ser compreendido a partir de dois aspectos: primeiro, como elemento da cultura corporal de movimento e, segundo, como conteúdo físico-esportivo do lazer. Marcellino (2012) considera seis os conteúdos/interesses do lazer, a saber: os interesses artísticos, intelectuais, manuais, sociais e o físico-esportivo, esses cinco com base em Dumazedier (1980), e o turístico, com base em Camargo (1979). Schwartz (2003) menciona o virtual como o sétimo conteúdo/interesse do lazer, o que, para alguns autores como Lopes da Silva e Fraga (2012), o virtual é um espaço para o acesso aos demais conteúdos. Para Lopes da Silva e Silva (2012), os conteúdos físicoesportivo do lazer são específicos da área da Educação Física, dentre os quais se inclui os esportes.

Esta investigação se propõe a responder ao seguinte questionamento: quais os significados dos projetos de esporte e lazer do IFNMG - Campus Januária para alunos participantes de tais projetos?

\section{Método}

Este trabalho trata-se de um estudo qualitativo. Para Minayo (1994, p. 21), esse tipo de pesquisa "trabalha com o universo dos significados, dos motivos, das aspirações, das crenças, dos valores e das atitudes". O procedimento metodológico utilizado foi a pesquisa bibliográfica e de campo. Na pesquisa bibliográfica foram utilizadas as técnicas de análise textual, temática, interpretativa, problematização e síntese pessoal, de acordo com Severino (2007). A pesquisa bibliográfica, primeira fase da investigação, foi efetuada a partir de um levantamento bibliográfico nos Sistemas de Bibliotecas da Universidade Metodista de Piracicaba (UNIMEP) e da Universidade Estadual de Campinas (UNICAMP), do Banco de Teses e Dissertações da Capes, do Google 
Acadêmico, do Portal Periódico Capes e de revistas especializadas, centradas em obras de autores da Antropologia, da Sociologia, do Esporte, do Lazer e da Educação Física. O levantamento bibliográfico foi realizado a partir das palavras-chave: lazer, educação física, esporte e cultura, combinadas entre si. Esse levantamento deu subsídios para a análise da pesquisa de campo realizada junto aos alunos que participam dos projetos de esporte e lazer do IFNMG - Campus Januária. A revisão bibliográfica foi realizada de abril a dezembro de 2014 .

A segunda fase da investigação consistiu na pesquisa de campo, aprovada pelo Comitê de Ética de Pesquisa em seres humanos da Universidade Metodista de Piracicaba (CEP - UNIMEP), protocolo no 86/2015, em que todos os sujeitos envolvidos na pesquisa assinaram o Termo de Consentimento Livre e Esclarecido. Essa fase da investigação teve como finalidade a identificação e análise dos significados dos projetos de esporte e lazer do IFNMG - Campus Januária para os alunos participantes que frequentam as aulas do Ensino Médio Integrado. No Ensino Médio Integrado estão os alunos que concluíram o Ensino Fundamental (9o Ano) e ingressaram em um dos cursos Técnicos Integrados ao Ensino Médio. Estes alunos têm aulas das disciplinas propedêuticas e técnicas.

A escolha pelo Campus Januária deveu-se ao fato de ser um dos campi com o maior número de cursos de Ensino Médio Técnico da região, maior número de alunos, melhor acessibilidade e maior estrutura física no setor de esporte e de lazer. Nesse campus tem participantes em eventos esportivos promovidos na região e pelos programas do governo municipal, estadual e federal, além de um corpo docente envolvido com os projetos de esporte e de lazer durante todo o ano. 
Consideramos participantes da nossa pesquisa os alunos do sexo masculino dos cursos Técnico em Agropecuária Integrado ao Ensino Médio e Técnico em Informática para Internet Integrado ao Ensino Médio. O fator determinante para a escolha dos alunos de tais cursos é a conveniência e facilidade que o pesquisador teve para encontrálos na instituição, pois os mesmos permaneciam na instituição durante todo o dia. O fato de todos os entrevistados serem do sexo masculino é porque os rapazes são maioria, em termos de participação, nos projetos de esporte e lazer. A pesquisa foi realizada com um número total de 10 alunos. Esse número foi considerado suficiente para os objetivos da pesquisa, já que consideramos como critério a saturação de dados, de acordo com Duarte (2002). Seis dentre os dez rapazes entrevistados deram uma resposta aproximada para a principal pergunta da investigação.

Para a seleção dos entrevistados utilizamos inicialmente um questionário que foi distribuído durante as aulas para os alunos do Ensino Médio Técnico Integrado ao Ensino Médio dos cursos de Informática para Internet e Agropecuária. As informações solicitadas aos alunos no questionário foram: nome, idade, telefone e e-mail (para que pudéssemos entrar em contato posteriormente), série, sexo e as questões:

1. Qual o curso do Ensino Médio Técnico Integrado que você está matriculado? (com alternativas de Técnico em Agropecuária e Técnico em Informática para Internet).

2. Em qual regime você se encontra no IFNMG - Campus Januária? (com as alternativas externo, interno e semi-interno). São três os regimes para os estudantes do Campus Januária: Externo, Interno e Semi-interno. No regime de internato, os alunos têm direito à moradia na escola; no semi-internato, os alunos permanecem por quase todo o dia na escola, com direito a café da manhã, almoço e lanche. Ambos os sistemas 
são para os alunos vindos de outros municípios da região. Já os alunos externos não têm nenhum desses direitos por serem residentes da cidade.

3. Faz alguma atividade esportiva ou de lazer no campus? (com as alternativas sim e não)

4. Já representou ou representa o campus como aluno-atleta em alguma competição esportiva? (com as alternativas de sim e não).

5. Participa dos projetos de esporte e de lazer do campus, treinamentos esportivos, danças, lutas, ginásticas, musculação? (com as alternativas de sim e não).

6. Pratica alguma modalidade esportiva no campus, no horário fora das aulas? (com as alternativas de sim e não).

Consideramos os sujeitos como integrantes do grupo investigado aqueles que disseram participar ou já ter participado dos projetos de esporte e lazer do campus e que conseguimos fazer contato posteriormente.

Após a seleção dos entrevistados, realizamos uma reunião para apresentar o projeto de pesquisa aos alunos e aos pais dos alunos menores de 18 anos e fazer a leitura e a entrega do Termo de Consentimento Livre e Esclarecido (TCLE) específico para os pais dos alunos menores e aos demais maiores de idade. Na reunião compareceram apenas os alunos. Aos menores de idade entregamos o documento para ser devolvido, assinado por eles e pelos pais no dia da entrevista.

$\mathrm{Na}$ pesquisa de campo, realizamos também a observação participante e a entrevista semiestruturada. A observação participante, de acordo com Bruyne et al. (1982), é uma técnica que nos dá acesso aos fatos tais como são para os sujeitos observados, complementando os dados obtidos com o questionário e as entrevistas semiestruturadas. No caso, fizemos observações nos espaços destinados à realização dos 
projetos de esporte e lazer do campus. O critério para a observação foi: a atitude dos alunos durante as atividades.

As entrevistas semiestruturadas são procedimentos considerados por Triviños (1987) como um dos principais meios na pesquisa qualitativa em Ciências Humanas e baseiam-se em questionários básicos que permitem ao informante seguir espontaneamente a linha de seu pensamento e de suas experiências.

O roteiro de entrevista foi:

1. Histórico de experiências esportivas e de lazer já vivenciadas nos anos anteriores no IFNMG - Campus Januária.

3. Conceito de esporte;

4. Conceito de lazer;

5. Significados atribuídos aos projetos de esporte e lazer no IFNMG - Campus Januária

As perguntas para iniciarmos as entrevistas foram (dependendo da resposta poderiam ser formuladas outras perguntas, a fim de atingirmos o objetivo da pesquisa):

1. Quais as práticas esportivas você já participou no IF Norte de Minas Campus Januária?

2. Como você vê o esporte dentro da escola?

3. Você vivenciou experiências de lazer em anos anteriores ao IF Norte de Minas Campus Januária?

4. O que é esporte para você?

5. O que é lazer para você?

6. O que significa para você as práticas dos projetos de esporte e de lazer no IF Norte de Minas - Campus Januária? 
A terceira fase consistiu nas análises dos dados coletados na pesquisa de campo.

Para isso, tivemos como base os princípios da pesquisa antropológica, o que Geertz (1989) compreende por "descrição densa". Para o autor, há quatro características esse tipo de descrição:

Ela é interpretativa; o que ela interpreta é o fluxo do discurso social e a interpretação envolvida consiste em tentar salvar o "dito" num tal discurso da sua possibilidade de extinguir-se e fixá-lo em formas pesquisáveis. Há ainda, em adiantamento, uma quarta característica de tal descrição, pelo menos como eu a pratico: ela é microscópica (p.31).

A finalidade dessa etapa da pesquisa foi interpretar os discursos dos alunos do Ensino Médio Técnico do Instituto Federal do Norte de Minas Gerais - Campus Januária. Não foi nossa intenção fazer uma "descrição densa" no sentido mais amplo de uma etnografia, nos moldes da pesquisa antropológica, mas utilizamos aqui os princípios etnográficos como referência para a análise que fizemos dos dados coletados. Portanto, procedemos ao nível da investigação da compreensão e do comportamento social em relação aos significados atribuídos às práticas dos projetos de esporte e de lazer para os sujeitos entrevistados.

Foi utilizado um aparelho de gravador digital Sony, modelo ICD-PX312, com 2 GB de memória, para a gravação de voz durante as entrevistas.

\section{Resultados e Discussão}

\section{Esporte, Lazer e Cultura no Âmbito Escolar}

$\mathrm{Na}$ perspectiva de entender o universo esportivo, a partir de um referencial sociocultural, autores como Rubio (2002), Garcia (2015) e Bento (2006) têm se dedicado ao estudo do tema com o propósito de obter dados que venham elucidar tal 
fenômeno. A nossa intenção ao estabelecer as relações entre esporte, sociedade, cultura e lazer, será para dar sustentação nas interpretações e análises da pesquisa realizada com os alunos participantes dos projetos de esporte e lazer do IFNMG - Campus Januária.

Com o aumento das práticas esportivas fica evidente o crescente número de praticantes formais e não formais do fenômeno esportivo na atualidade. De acordo com Rubio (2002):

O esporte é na atualidade um dos principais fenômenos sociais e uma das maiores instituições do planeta. [...] além de tornar um dos principais elementos da indústria cultural contemporânea, matériaprima dos meios de comunicação de massa e uma das poucas formas reconhecidamente honestas de rápida ascensão social (p. 130).

Este prestígio conferido ao esporte na sociedade contemporânea está relacionado ao fato de como esse fenômeno sociocultural tem sido consumido, não somente como elemento de rendimento esportivo e de espetáculo, como também de modo recreativo e educacional. Em virtude das suas características construídas ao longo da história, de como foi moldado e como veio se transformando em um componente hegemônico da cultura corporal de movimento na sociedade, o esporte de rendimento tem se tornado espelho para as demais dimensões. Neste sentido, o esporte passa a ser objeto de estudo da Sociologia, pois é praticado e consumido por diferentes grupos sociais.

O esporte praticado na escola tem uma estrutura recreativa ou de participação, pois os sujeitos praticantes não vivem exclusivamente do fenômeno, o ambiente não é específico para o alto rendimento, porém os participantes podem vivenciar uma prática com predomínio dos valores do alto rendimento. Existe ainda, a possibilidade de, no futuro, os alunos viverem do esporte e se tornarem atletas profissionais.

Para compreendermos o esporte como fenômeno cultural da sociedade contemporânea, temos que entender como tal elemento se insere na vida dos sujeitos, 
que valores, sentidos e significados são atribuídos ao esporte pelos sujeitos envolvidos. Neste sentido, primeiro procuramos compreender o que é cultura e tomamos como base os estudos da Antropologia Social. Para Geertz (1989, p.15), a cultura é a construção de significados, sendo seu conceito essencialmente semiótico.

[...] acreditando como Max Weber que o homem é um animal amarrado a teias de significados que ele mesmo teceu, assumo a cultura como sendo essas teias e a sua análise; portanto, não como uma ciência experimental em busca de leis, mas como uma ciência interpretativa, à procura do significado. É justamente uma explicação que eu procuro, ao construir expressões enigmáticas na sua superfície.

O conceito de cultura de Geertz (1989) é fundamental para compreendermos os conflitos entre grupos heterogêneos e, entre esses grupos, a singularidade de cada sujeito que convive em determinado espaço, como é o caso dos alunos participantes dos projetos esportivos e de lazer do IFNMG - campus Januária.

Daolio (2013, p.33), ao afirmar que "A natureza do homem é ser um ser cultural, ao mesmo tempo, fruto e agente da cultura", leva-nos a compreender que o ser humano não é apenas biológico. Ao mesmo tempo em que ele recebe cultura, ele produz cultura. São as relações sociais estabelecidas que irão influenciar a vida do ser humano no meio em que vive. Os lugares, os familiares e o meio podem influenciar na formação cultural e isso é o que diferencia o ser humano dos outros animais.

Ao se referir às diferentes formas do corpo de se expressar, Daolio (2013) conclui que as mesmas são expressões simbolicamente construídas pela tradição de um povo, ou seja, cada sociedade tem uma tradição particular de se expressar por meio do corpo. Essa tradição é repassada de geração para geração.

É inevitável falarmos de esporte e cultura no ambiente escolar e não relacionarmos com a Educação Física - componente curricular obrigatório do Ensino 
Básico que trata dos elementos da cultura corporal de movimento, os jogos, as ginásticas, as danças, os esportes e as lutas - que, nos dias de hoje, tem privilegiado o esporte com base no alto rendimento, esporte hegemônico, que valoriza prioritariamente os aspectos técnicos, táticos e regras reguladoras nas diferentes modalidades. Por outro lado, segundo Daolio (2004), as Ciências Humanas têm influenciado a Educação Física com base nos conhecimentos da Antropologia, da História, da Sociologia, da Ciência Política, entre outras, e têm avançado, sobretudo, em uma perspectiva cultural, como afirma o autor logo no início da introdução de sua obra "Educação Física e o conceito de cultura":

[...] cultura é o principal conceito para a educação física, porque todas as manifestações corporais humanas são geradas na dinâmica cultural [...] expressando-se diversificadamente e com significados próprios no contexto de grupos culturais específicos (DAOLIO, 2004, p. 2).

Nesse sentido, em nosso estudo, vamos para além das aulas de Educação Física, estamos nos referindo aos demais espaços e aos projetos esportivos e de lazer no âmbito escolar, que tem como tradição a Educação Física como referência. As práticas dos projetos de esporte e lazer no Campus Januária são desenvolvidas geralmente pelos mesmos professores que atuam nas aulas de Educação Física. Estes utilizam as aulas para observar os alunos que têm aptidões em uma determinada modalidade para compor as equipes esportivas do campus inseridas nos projetos de treinamentos.

Os treinamentos esportivos são práticas esportivas que fazem parte dos projetos pedagógicos institucionais e objetivam a participação dos alunos em competições. Configuram-se em uma prática que tem semelhança ao modelo de esporte do alto rendimento em diversas modalidades. Para os alunos que são selecionados por meio de seletivas, resta a dedicação para continuarem participando das atividades extraescolares que compõem os projetos de esporte e lazer da instituição. 
Concordamos com Garcia (2015) quando o autor procura conceituar o esporte a partir de um referencial sociocultural, tendo como base as técnicas individuais de cada sujeito. De acordo com o autor, o conceito de esporte é "uma estrutura de sentidos proporcionados pela cultura que atribui determinados significados e valores aos diferentes movimentos humanos, numa clara inter-relação entre os planos individual e social" (GARCIA, 2015, p. 16). O mesmo autor compreende o ser humano como central aos estudos sobre esporte. Para ele, "pensar no desporto implica, antes de tudo, pensar no ser humano. E o ser humano, ao praticar o desporto, não é menos importante do que em qualquer outra situação da vida" (GARCIA, 2015, p. 36). Desse modo, entendemos que, de acordo com Garcia (2015), para compreender o desporto primeiro devemos compreender o ser humano, pois é ele quem vai dar sentido ao esporte, independentemente de qual modalidade ele pratica, do espaço em que ele se encontra. $\mathrm{O}$ esporte para esse autor se insere em inúmeras dimensões da vida do ser humano e o mesmo considera o esporte um fenômeno social total.

O autor português Bento (2006), com diversas publicações no Brasil, entende o esporte como algo muito mais amplo do que apenas sinônimo de uma prática de modalidade esportiva. De acordo com Bento (2006, p. 155), o desporto é “(...) como um conjunto de tecnologias corporais, sendo o uso destas balizado por razões e padrões culturais e por intencionalidades, metas e valorizações sociais”. Nessa perspectiva, consideramos que o autor entende o esporte não só como um exercício físico ou uma atividade regulada, controlada com objetivos de alcançar metas, mas como algo em uma dimensão muito mais ampla, plural, presente nas manifestações corporais dos indivíduos, inserido em determinados contextos históricos, de modo que os sujeitos podem expressar-se. 
Assim, as ideias de Garcia (2015) e Bento (2006) são complementares a nosso ver e contribuem para pensá-lo sobre o esporte de modo a considerá-lo uma construção humana e social.

Os sujeitos vão ao longo da vida escolar se apropriando da cultura corporal de movimento, que é a especificidade da educação física, e mais tarde esses conhecimentos poderão influenciar suas escolhas no que se refere às práticas esportivas realizadas no tempo disponível.

De acordo com Marcellino (2013), o lazer deve ser vivenciado no "tempo disponível" e em caráter desinteressado e, na escola, pode ser entendido a partir do duplo processo educativo - educação para e pelo lazer. A educação para o lazer pode ocorrer tanto na escola no momento das aulas nas diferentes disciplinas escolares como no tempo disponível dos alunos no contraturno das aulas ou fins de semana, mediante uma ação pedagógica com o intuito de viabilizar aos sujeitos o acesso a conhecimentos sobre o lazer, conhecimentos esses que poderão ampliar suas possibilidades de atividades e de reflexões sobre o lazer. Já a educação pelo lazer só pode ocorrer no tempo disponível dos sujeitos, no caso da escola, no contraturno das aulas ou aos fins de semana, pois nesse tempo crianças e jovens podem fazer as escolhas das atividades que querem participar, já que não são obrigatórias. O processo educativo, nesse caso, ocorre por meio das atividades vivenciadas pelos alunos. Será que tais projetos esportivos e de lazer que exigem a regularidade do aluno e eficiência deles em relação aos treinamentos e às competições no IFNMG - Campus Januária podem ser considerados como atividades do contexto do lazer?

Para melhor compreensão desse fenômeno, partiremos do conceito de lazer elaborado por Marcellino (2013, p. 29), que diz: 
Dessa forma, prefiro entender o lazer como a cultura - compreendida no seu sentido mais amplo - vivenciada (praticada ou fruída) no "tempo disponível". O importante, como traço definidor, é o caráter "desinteressado" dessa vivência. Não se busca, pelo menos fundamentalmente, outra recompensa além da satisfação provocada pela situação. A "disponibilidade de tempo" significa possibilidade de opção pela atividade prática ou contemplativa.

Com base nesse conceito de lazer de Marcellino (2013), fundamentado em um referencial sociocultural, investigamos os significados atribuídos aos projetos de esporte e lazer para os alunos do IFNMG - Campus Januária. Os projetos esportivos do campus são práticas que acontecem no âmbito escolar e no contraturno das aulas, ou seja, têm um caráter extracurricular e são programadas e desenvolvidas pelos professores de Educação Física, que têm como principal objetivo a participação dos alunos nos eventos esportivos competitivos. Os alunos por sua vez podem optar ou não por participarem dessas atividades. Por essas características compreendemos que os projetos de esporte e lazer do IFNMG - Campus Januária compõem um conjunto de modalidades esportivas a serem vivenciadas no contexto do lazer dos alunos, ainda que possamos questionar os valores que predominam nesses projetos - sendo a competição o central. No entanto, mesmo com um conjunto de valores que são referência para o esporte de alto rendimento, os alunos que participam dos projetos podem negociar tais valores ou mesmo construir outros, já que eles sim, alunos, são produtores de cultura e atribuem um conjunto de significados às práticas que realizam. A seguir apresentaremos os resultados da pesquisa de campo.

\section{A pesquisa de Campo}

Em nosso estudo foram selecionados 10 alunos que atendiam ao perfil para a realização das entrevistas, que foram gravadas e depois transcritas. Utilizaremos as 
iniciais PM (Participante Masculino), enumeradas de 01 a 10 para manter o sigilo dos entrevistados.

Os participantes masculinos dos projetos esportivos e de lazer do Campus Januária são alunos que participam ou já participaram dos projetos desenvolvidos na instituição. Os entrevistados selecionados são, na maioria, externos, das turmas do segundo e do terceiro anos dos cursos de Informática e Agropecuária, com idades entre 16 e 19 anos, como podemos acompanhar na tabela abaixo em detalhes.

Tabela 1 - Especificações dos entrevistados

\begin{tabular}{llllll}
\hline Alunos & Série & Curso & Regime & Idade \\
\hline PM - 01 & $2^{0}$ ano & Info & $\begin{array}{l}\text { Semi- } \\
\text { interno }\end{array}$ & 16 anos \\
PM - 02 & $3^{0}$ ano & Agro & $\begin{array}{l}\text { Externo } \\
17 \text { anos }\end{array}$ \\
PM - 03 & $3^{0}$ ano & Info & $\begin{array}{l}\text { Semi- } \\
\text { interno }\end{array}$ & 17 anos \\
PM - 04 & $3^{0}$ ano & Info & Externo & 19 anos \\
PM - 05 & $3^{0}$ ano & Info & Externo & 17 anos \\
PM - 06 & $3^{0}$ ano & Agro & Interno & 18 anos \\
PM - 07 & $2^{0}$ ano & Info & Semi- & 16 anos \\
interno & \multirow{2}{*}{$\begin{array}{l}\text { Externo } \\
\text { PM - 08 }\end{array}$} & $2^{0}$ ano & Info & Enos \\
PM - 09 & $2^{0}$ ano & Info & Externo & 16 anos \\
PM - 10 & $3^{0}$ ano & Info & Externo & 17 anos \\
\hline
\end{tabular}

As respostas dadas na primeira questão - "de quais práticas esportivas você já participou no IFNMG - Campus Januária?” - foram bem diversificadas entre os entrevistados. As principais foram futsal, judô, futebol de campo, handebol, musculação, vôlei, xadrez e tênis de mesa.

O futsal foi citado por quatro diferentes entrevistados: os PM (02, 04, 05 e 08), assim como o judô e o futebol de campo, na sequência como as modalidades mais 
praticadas. As práticas menos citadas em suas respostas foram o xadrez, o tênis de mesa (PM-10) e a natação, que também foi citada apenas uma única vez pelo entrevistado (PM-03).

As práticas citadas pela maioria foram as modalidades tradicionais praticadas principalmente nas aulas de Educação Física e que são amplamente valorizadas pela mídia e pelas aulas de Educação Física escolar. O judô, como uma das modalidades que aparece nas respostas dos alunos entrevistados, está relacionado ao fato de o professor criar um projeto específico da modalidade no campus. Outro ponto identificado para a modalidade aparecer entre as mais citadas, se deve ao fato de haver uma possibilidade de o Campus Januária representar o IFNMG na etapa da região sudeste nessa modalidade nos Jogos dos Institutos Federais nas cidades de Muzambinho - MG e Machado - MG. Essas informações foram observadas durante os treinos dos alunos. A maioria dos alunos entrevistados menciona mais de uma prática como podemos observar nas respostas a seguir.

\footnotetext{
Além daquelas básicas que a gente vê na prática da aula de Educação Física, já fiz a musculação na academia e o judô. Tive oportunidade também de treinar no time de handebol da escola (PM-01).

Bom, eu participo da Educação Física, então, já passou aí o vôlei, handebol, futsal e agora estou no projeto judô, que o professor começou passando na Educação Física, também musculação na academia da escola [...] (PM-08).

Natação (PM 03).

Xadrez, tênis de mesa e vôlei (PM-10).
}

As respostas dos alunos vão ao encontro das observações feitas durante o período que estivemos no campus. Os espaços e os profissionais de Educação Física são responsáveis por incentivar os alunos a essa diversificação das modalidades. Notamos 
que os entrevistados PM-01 e PM-08 fazem referência às suas experiências com as aulas de Educação Física e aos projetos ofertados no campus. Outro fator que notamos é que quando PM-01 fala da oportunidade de jogar na equipe de handebol, percebemos durante a entrevista que, para ele, isso é um orgulho, que se relaciona à ideia de representar a instituição onde estuda.

Ao perguntarmos "Como os alunos veem o esporte dentro da escola?" as respostas foram bem variadas. A maioria aponta para uma visão funcionalista da prática como: “tirar o stress" (PM-02,03, 07,08), "saudável” (PM-01 e 07), “melhora o desempenho físico" (PM-10), “afasta das drogas" (PM-04), "tirar um pouco o foco dos estudos" (PM-08), "sair da rotina de estudar de manhã e de tarde" (PM-09). Outros apontam o esporte como "oportunidade de desenvolver uma prática esportiva [...] oportunidade de viajar, conhecer pessoas diferentes, ampliar conhecimentos [...]" (PM05), "momento de descontração" (PM-03), "forma de aproximar os alunos", “socialização" (PM-01 e 06) e "competição" (PM-08).

A maneira como os alunos compreendem o esporte na escola traz elementos importantes para o nosso debate. Um deles é o discurso muito forte existente em nosso contexto social, em que o esporte, por si só, é a solução para os problemas sociais, de que por meio do esporte podemos solucionar as mazelas sociais da sociedade, melhorar as condições de vida dos cidadãos no que se refere à saúde, ao caráter, ao bem-estar, questões sociais que podem ter resultados positivos com a prática esportiva, mas que sua efetiva solução envolve ações relacionadas às políticas públicas, principalmente. Os alunos são conscientes e valorizam a importância do esporte como uma das possibilidades de atividades no contexto do lazer dentro da escola, que viabiliza a eles estabelecerem melhores relações dentro e fora da instituição escolar, assim como 
ampliar suas possibilidades de diversificação de atividades no contexto do lazer. Esse entendimento, é nítido nas observações feitas e em outras respostas dadas durante as entrevistas, em que o esporte vivenciado no âmbito escolar, independentemente do tipo de manifestação, não se restringe apenas ao alívio do stress, melhoria da saúde e muito menos à possibilidade de tirar as pessoas das drogas, mas sim à possibilidade de ampliar os conhecimentos e construir novos valores. Para exemplificar como tal fato se explica, durante os treinamentos os alunos demonstram ter aprendido técnicas e táticas do jogo e também a respeitar o próximo.

Em nossa questão sobre "Você vivenciou experiências de lazer em anos anteriores ao IFNMG - Campus Januária?", todos os alunos responderam que sim. Ao perguntarmos sobre o conceito de lazer, muitos deles relacionam o lazer à diversão, distração, ao não fazer nada, ao prazer de fazer algo que gosta. Outros arriscaram uma definição como: uma brincadeira sem regras, outros confundiram a definição do lazer com o esporte.

Nas falas dos sujeitos observamos como fica evidente a percepção dos alunos em relação ao que eles compreendem sobre lazer, citam diversos interesses do lazer, como podemos observar na fala a seguir.

Lazer, muitas vezes, se confunde com esporte porque todo esporte que você faz por livre e espontânea vontade é uma forma de lazer, mas também não fica só no lá... só no esporte, pode ser outras coisas, às vezes você tocar um violão é ... às vezes fazer uma caminhada, às vezes só uma conversa entre amigos já é uma forma de lazer (PM-01).

Momento de felicidade, né? De a pessoa fazer umas coisas que gosta. Ser feliz, para mim, é jogar bola, é o meu lazer [...] (PM-04).

Lazer são brincadeiras entre amigos de... tipo no futebol, assim, você bater uma pelada, sem muita regra, só "colegage" mesmo, tem uma falta ali, você para por parar mesmo, porque tem amizade com o cara aí [...] Sem muitas regras, você mesmo faz suas regras, se foi falta você mesmo interrompe, cobra a falta ali, se a bola saiu ou não você mesmo que decide[...] (PM-07). 
Podemos notar que a referência que os entrevistados têm sobre lazer está relacionada predominantemente ao conteúdo físico-esportivo. No entanto, o entrevistado PM-01 demonstra compreender o esporte ao relatar outros interesses como o artístico e o social. Para os entrevistados PM-04 e 07, o fato de se fazer o que gosta de forma lúdica, despreocupados e no tempo "livre" também tem demonstrado a forma como os alunos compreendem o lazer. Em conformidade com o treino de handebol podemos observar que a maneira como os entrevistados se manifestaram está relacionada à forma como eles compreendem o esporte e o lazer no âmbito escolar. Existe o compromisso dos treinamentos, no entanto, no momento do jogo eles se sentem "livres" para jogar à sua maneira, quebrando a rigidez característica do esporte de alto rendimento.

Sobre a pergunta: "Além do jogar bola ou praticar esporte teve outra forma de vivenciar o lazer?" As respostas foram: sair com os amigos e divertir-se. Ou seja, mais uma vez o interesse social também predomina em suas falas, o divertimento e o prazer de estar com amigos são elementos presentes nas respostas dos entrevistados.

Quando perguntamos sobre o conceito de esporte, as respostas são muito parecidas. Quase todas foram voltadas para os benefícios do esporte para os sujeitos. As palavras que mais apareceram nas entrevistas foram: saúde, atividade física, exercício físico e mental, estilo de vida, alívio do stress diário, ou seja, termos que levam à compreensão da prática esportiva em sentido compensatório das atividades do dia a dia. Outros relacionaram o esporte aos problemas sociais na sociedade, tais como: tirar jovens e adolescentes das drogas. 
O esporte seria uma atividade física que você faz, ou até mental, pra você melhorar seu corpo, sua mente e de alguma forma te ajudar. [...] No meu caso, além de querer melhorar visualmente, eu queria melhorar fisicamente, pois a minha pressão de vez em quando desequilibrava... Aí, com a musculação, ela começou a controlar, foi controlando e tal, aí foi perdendo os problemas, foi perdendo a bronquite, perdi as dores de cabeça, perdi o cansaço fácil, que já era um problema da pressão, melhora, você se sente bem (PM-02).

É, não sei se é só comigo, mas sei lá, não consigo ficar parado, então o esporte é uma forma de... de dar o máximo, entendeu? Como o judô mesmo. Tem dia que saio daqui morto de cansado, mas á é aquele cansaço de, como posso dizer, é aquele cansaço prazeroso, entendeu? Como praticava futsal, então, é a coisa que eu mais gosto de fazer (risos) (PM-09).

Uma coisa que eu faço, que faz eu me sentir bem, que faz bem para minha saúde. Uma coisa prazerosa! (PM-01)

Esporte, para mim, é um estilo de vida [...], é saúde (PM-05).

A compreensão que os alunos entrevistados têm do esporte é o mesmo que é amplamente divulgado pela mídia e que circulam no cotidiano, podendo ser reforçado em escolas, academias, clubes etc., por meio de propagandas, programas esportivos, relacionando o esporte à saúde, à qualidade de vida, ao bem-estar, ao alívio do stress, entre outros discursos associados a tal fenômeno. De acordo com Rubio (2002), o esporte é matéria-prima para os meios de comunicação de massa. Essa transmissão massificada de informações à população pode influenciar e/ou até induzir os entrevistados em suas respostas ao relacionar o esporte à saúde, ao estilo de vida, aos significados que as práticas esportivas têm para eles em seu cotidiano. No entanto, devemos considerar também que, para além do discurso da mídia e de instituições que promovem o esporte, a prática regular de alguma modalidade esportiva, de fato, pode gerar benefícios aos sujeitos com relação aos aspectos fisiológicos, trazendo implicações para a saúde dos sujeitos. 
Para PM-05, 01 e 09, o esporte tem que ser algo prazeroso para ser desfrutado com intensidade. Bento (2006) afirma que o esporte não pode ser entendido apenas como exercício físico, ou atividade regulada, mas em uma dimensão muito mais ampla, plural, que seja interligada aos contextos históricos e culturais dos sujeitos. O entusiasmo e a satisfação pelas práticas foram observados nos treinos de handebol e de judô, no jogo de peteca, em outras atividades que tivemos oportunidade de observar. Os alunos esboçavam prazer pelas atividades que estavam realizando.

A pergunta-chave da nossa pesquisa foi: "O que significa para você as práticas dos projetos de esporte e lazer no IFNMG - Campus Januária?”, as respostas que mais se repetiram foram: saúde, oportunidades e socialização.

Ah, para mim, é uma oportunidade, né? Tanto de diversão, competição, como uma das formas de você poder deixar sua lembrança do instituto, né? Assim, eu estudei no instituto, formei, pude e tive a oportunidade de participar de tais modalidades esportivas (PM-08).

Bom, eu acho que seria, principalmente, acima de tudo, as relações que eu fiz com muitas pessoas, os laços de amizade que ficaram. Com pessoas às vezes de outros institutos, em competições de outros estados, seria isso (PM-10).

Ah... acredito que toda forma de quebrar a rotina, para mim, é boa, é ótima, ainda mais para mim que sou ansioso, ah, então para mim só atrapalha você ficar todo dia fazendo a mesma coisa, todo dia saber o que vai acontecer [...], deixa ansioso, isso me atrapalha, você fica com a cabeça, aí vem o nervoso, sem necessidade. Aí, quando tem esses momentos você acaba, como dizer, é... fugindo da realidade por um momento, não que não seja ideal... Aí, quando volta, você volta, é outra pessoa, além de ser bom para saúde, né?, de quem pratica (PM03).

Para os entrevistados participantes dos projetos de esporte e lazer do IFNMG Campus Januária, a saúde, o lazer e as oportunidades de socialização foram mencionadas como principais significados atribuídos aos projetos existentes no campus. Os entrevistados PM - 08, 04, 05 e 01 citaram as oportunidades que os projetos 
possibilitam, como competir pela instituição e deixar o seu legado, de ser reconhecido no campus por representar a instituição, de viajar e conhecer novos lugares e de se divertir, ou seja, para eles, os projetos são além de um momento de competição, também de produção de novos significados e valores. Os entrevistados PM -10, 01, 02 , 03, 06 e 07 mencionaram as relações que foram estabelecidas durante as competições fora da instituição, principalmente durante as viagens, os laços de amizades que foram construídos e, para os entrevistados PM - 03, 02 e 06, os projetos são uma forma de quebrar a rotina do cotidiano escolar, de manter o bem-estar físico, o que, para eles, é importante devido às questões de manter o corpo saudável.

Ao final da entrevista deixamos os entrevistados à vontade para complementarem as suas ideias e a maioria deles fez menção a criação de mais projetos relacionados ao esporte e parabenizou o IFNMG- Campos Januária por ter essa iniciativa de estar desenvolvendo tais projetos. Por outro lado, alguns aproveitaram também para queixar-se da rotina de obrigações que os alunos têm durante a semana o que, segundo eles, prejudica a participação nos projetos de esporte e lazer.

\section{Considerações Finais}

O esporte na escola é um dos principais conteúdos das aulas de Educação Física. Por outro lado, no contexto do lazer, o esporte é também presente no cotidiano da maioria das atividades dos alunos, compreendido como o interesse físico-esportivo do lazer. Neste estudo, procuramos analisar os dois fenômenos, o esporte e o lazer, a partir de um referencial sociocultural. Para identificar os significados que os estudantes atribuem aos projetos de esporte e lazer do IFNMG - Campus Januária compreendemos 
inicialmente que o ser humano é um ser social imerso em um determinado contexto cultural.

Os participantes dos projetos de esporte e lazer do IFNMG - Campus Januária revelaram que o seu principal interesse em fazer parte das equipes esportivas está associado à possibilidade de viagens para a participação nas competições fora da cidade. Com isso, os alunos valorizam outro interesse do lazer, o turístico. Há também uma menção dos alunos participantes em serem reconhecidos pelos seus talentos e terem a oportunidade de se tornarem atletas profissionais.

Percebemos que os alunos participantes dos projetos de esporte e lazer do IFNMG -campus Januária têm um conhecimento básico sobre as atividades que desenvolvem. A maioria das respostas apontam para uma visão compensatória da prática vivenciada (quebra da rotina de vida, obter benefícios para a saúde etc.). No entanto, o conjunto das respostas indica outros significados dos projetos investigados. A maioria dos alunos afirmam que os projetos de esporte e lazer são importantes em suas vidas pelo fator da oportunidade de socialização, competição e pela diversão, ou seja, além da vivência do esporte e lazer de forma compensatória, os projetos do campus Januária também contribuem com a construção de valores e sentidos na vida dos sujeitos participantes.

O conhecimento aqui produzido poderá contribuir para o debate na área da Educação Física no que diz respeito às possibilidades de práticas esportivas e de lazer no âmbito escolar. Seria interessante se a instituição investigada propusesse um projeto de educação para e pelo lazer, de modo a viabilizar aos alunos o acesso ao conhecimento sobre tal fenômeno, assim como do esporte. Seria interessante também que os profissionais envolvidos com esse modelo de projeto fizessem uma reflexão, na 
perspectiva de se criar propostas que sejam diversificadas e que possam atender um número maior de estudantes e envolver toda a comunidade escolar, alunos, pais, servidores técnicos administrativos e professores, proporcionando aos educandos e a todos os envolvidos o acesso ao esporte e lazer.

\section{REFERÊNCIAS}

BENTO, J. O. Corpo e Desporto: reflexões em torno desta relação. (2006). In: MOREIRA, W. W. (Org.). Século XXI a era do corpo ativo. Campinas: Papirus, 2006.

BRUYNE et al. Dinâmica da pesquisa em ciências sociais. 3. ed. Rio de Janeiro: Francisco Alves, 1982.

CAMARGO, O. L. Recreação Pública Cadernos de Lazer. 4. ed. São Paulo: SESC, p. 29-36, 1979.

DAOLIO, J. Educação Física e o conceito de Cultura. Campinas: Autores Associados, 2004.

Da cultura do corpo. 17. ed. Campinas: Papirus, 2013.

DUARTE, R. Pesquisa qualitativa: reflexões sobre o trabalho de campo. Cadernos de pesquisa, n.115, São Paulo, p. 139-154, 2002.

DUMAZEDIER, J. Valores e conteúdos culturais do lazer. São Paulo: Sesc, 1980.

GARCIA, R. P. No Labirinto do desporto: horizontes culturais contemporâneos. Belo Horizonte. Casa da Educação Física, 2015.

GEERTZ, C. A interpretação das culturas. Rio de Janeiro: LTC,1989.

LOPES DA SILVA, C., SILVA, T. P. Lazer e Educação Física: textos didáticos para a formação de profissionais do lazer. Campinas: Papirus, 2012.

MARCELLINO, N.C. Estudos do lazer: uma introdução. 5. ed. Campinas: Autores Associados, 2012.

N. C. Lazer e Educação. 17. ed. Campinas: Papirus, 2013.

MINAYO, M. C. de S. Ciência, técnica e arte: o desafio da pesquisa social. In: (Org.). Pesquisa Social. Petrópolis: Vozes, 1994.

RUBIO, K. Do Olimpo ao Pós-Olimpismo: elementos para uma reflexão sobre o esporte atual. Rev Bras de Educ Fís e Esporte, v.16, n. 2, São Paulo, p.130-143, 2002. 
SCHWARTZ, G. M. O conteúdo virtual do lazer: contemporizando Dumazedier. Licere, v. 6, n. 2, Belo Horizonte, p. 23-31, 2003.

SEVERINO, A. J. Metodologia do Trabalho Científico. São Paulo: Editora Cortez, 2007.

TRIVIÑOS, A. N. S. Introdução à pesquisa em ciências sociais: a pesquisa qualitativa em educação. São Paulo: Atlas, 1987.

\section{Endereço dos Autores:}

Romualdo Ferreira dos Santos

Instituto Federal do Norte de Minas Gerais

Rodovia MG 202, KM 07 S/N - Zona Rural

Arinos - MG - 38680-000

Endereço Eletrônico: romuhfs@hotmail.com

Cinthia Lopes da Silva

Universidade Metodista de Piracicaba

Secretaria do Programa de Pós-graduação em Ciências do Movimento Humano

Rodovia do Açúcar, s/n km 156

Piracicaba - SP - 13.423-170

Endereço Eletrônico: cinthialsilva@uol.com.br 